\title{
The Investigation of Field Plate Design in 500 V High Voltage NLDMOS
}

\author{
Donghua Liu, ${ }^{1,2}$ Xiangming Xu, ${ }^{1,2}$ Feng Jin, ${ }^{1,2}$ Wenting Duan, ${ }^{2}$ Huihui Wang, ${ }^{2}$ Jing Shi, \\ Yuan Yao, ${ }^{2}$ Jun Hu, ${ }^{2}$ Wensheng Qian, ${ }^{2}$ Pengfei Wang, ${ }^{1}$ and David Wei Zhang ${ }^{1}$ \\ ${ }^{1}$ State Key Laboratory of ASIC and System, School of Microelectronics, Fudan University, Shanghai 200433, China \\ ${ }^{2}$ Huahong Grace Semiconductor Manufacturing Corporation, Shanghai 201206, China
}

Correspondence should be addressed to David Wei Zhang; dwzhang@fudan.ede.cn

Received 21 January 2015; Accepted 15 February 2015

Academic Editor: Rui Zhang

Copyright (C) 2015 Donghua Liu et al. This is an open access article distributed under the Creative Commons Attribution License, which permits unrestricted use, distribution, and reproduction in any medium, provided the original work is properly cited.

This paper presents a $500 \mathrm{~V}$ high voltage NLDMOS with breakdown voltage $\left(V_{\mathrm{BD}}\right)$ improved by field plate technology. Effect of metal field plate (MFP) and polysilicon field plate (PFP) on breakdown voltage improvement of high voltage NLDMOS is studied. The coeffect of MFP and PFP on drain side has also been investigated. A $500 \mathrm{~V}$ NLDMOS is demonstrated with a $37 \mu \mathrm{m}$ drift length and optimized MFP and PFP design. Finally the breakdown voltage $590 \mathrm{~V}$ and excellent on-resistance performance $\left(R_{\mathrm{sp}}=7.88 \mathrm{ohm}\right.$ $* \mathrm{~mm}^{2}$ ) are achieved.

\section{Introduction}

For the high voltage NLDMOS in BCD (Bipolar, CMOS, and DMOS) platform implicated in $500 \mathrm{~V}$ and even higher voltage, RESURF (reduced surface field) technology has been widely adopted $[1,2]$. The major purpose of this method is to increase the breakdown voltage $\left(V_{\mathrm{BD}}\right)$ and improve the on resistance $\left(R_{\mathrm{sp}}\right)$ of NLDMOS through the reduction of the surface electric field of drift region. It not only helps to reduce the NLDMOS device size and $R_{\mathrm{sp}}$, but also can meet breakdown requirement. For NLDMOS, one well-known technical approach is to introduce a p-type doped layer into n-type doped drift region and then realize the double RESURF or triple RESURF effect $[3,4]$. This approach also has been extensively studied by many researchers $[5,6]$.

MFP or gate shield (Gshield) is a common method employed in RFLDMOS. One or two (even three) metal field plates cover on gate and part of adjacent drift region [7]. The function of this Gshield is to shield the impact from drain and reduce the miller capacitance, which is the feedback capacitance between gate and drain $\left(C_{\mathrm{ds}}\right)$. It improves the frequency characteristics of RFLDMOS and extends the application to higher frequency [8]. This metal field plate will change the electric field distribution of drift region and affect the breakdown voltage of the device.
In the published research results for $500 \mathrm{~V}$ and higher voltage NLDMOS, some researches refer to the devices structure with field plate [9-11]. However, in-depth study of metal and polysilicon field plate on such high voltage NLDMOS is still needed for further investigation. This paper presents a detailed study of MFP and PFP and their effect on $500 \mathrm{~V}$ high voltage NLDMOS. A $500 \mathrm{~V}$ NLDMOS optimized by MFP and PFP design has been demonstrated with smaller drift size and higher enough breakdown voltage. This research result also can be adopted as a good reference for other high voltage NLDMOS developments.

\section{Device Structure}

The schematic cross section of $500 \mathrm{~V}$ NLDMOS device is showed in Figure 1. When drain terminal is biased at operation voltage $\left(V_{\mathrm{dd}}\right)$, the voltage sustained in lateral direction and vertical direction is the same. The breakdown voltage of both directions needs to be higher than the operation voltage and at least has $10 \%$ margin. Figure 1 shows that the drift region of NLDMOS embraces deep n-type well (DNW) and p-type buried layer (PBL). The voltage drop of $V_{\mathrm{dd}}$ in the vertical direction mostly is allocated to the PN diode formed by DNW and p-type substrate (PSUB). Its breakdown 
TABLE 1: Key reference sizes of this NLDMOS.

\begin{tabular}{lcc}
\hline Item & Description & Size \\
\hline PFP1 & Polysilicon field plate, source side & 7 \\
PFP2 & Polysilicon field plate, drain side & 10 \\
MFP1 & Metal field plate, source side & 22 \\
MFP2 & Metal field plate, middle & 3 \\
MFP3 & Metal field plate, drain side & 25 \\
E1 & MFP3 extending PFP2 (left side) & 8 \\
\hline
\end{tabular}

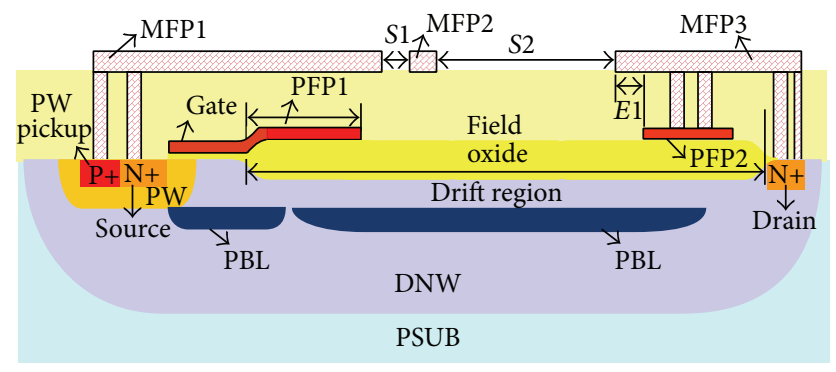

FIGURE 1: Schematic cross section of high voltage NLDMOS.

is higher than $1000 \mathrm{~V}$ and can be used in the application of $500 \mathrm{~V}$ NLDMOS. The drift region with DNW and PBL is designed considering RESURF effect. Drift region is fully depleted and sustains the lateral voltage when drain is biased. The doping condition of the drift region is determinate due to the technology platform and will not be discussed here. P-type well (PW) and p-type heavily doped region $(\mathrm{P}+)$ form the channel region. $\mathrm{N}$-type heavily doped region $(\mathrm{N}+)$ forms the source and drain. Above the silicon, there are polygate, polysilicon field plate 1 (PFP1, close to source side), polysilicon field plate 2 (PFP2, close to drain side), metal field plate 1 (MFP1, source side), metal field plate 2 (MFP2, middle), and metal field plate 3 (MFP3, drain side). $S 1$ is the space between MFP1 and MFP2. S2 is the space of MFP2 and MFP3. E1 represents the extension size of MFP3 over PFP2.

The effect of metal filed plate and polysilicon field plate on high voltage NLDMOS is investigated in this paper. Table 1 summarizes the key reference sizes of the device in Figure 1, which is a high voltage NLDMOS with $V_{\mathrm{BD}}=772 \mathrm{~V}$ and drift region length $=67 \mu \mathrm{m}$.

The depth of DNW is $8 \mu \mathrm{m}$ and the thickness of gate oxide is $43 \mathrm{~nm}$. The field oxide thickness of PFP and MFP is $630 \mathrm{~nm}$ and $1 \mu \mathrm{m}$, respectively.

\section{Experiment Results and Discussion}

The breakdown voltage of high voltage device depends on the length of drift region if the drift region can be fully depleted. When the bias voltage of drain keeps on a rise, the electric field intensity will reach the critical value of silicon $\left(E_{c}\right)$ and device breakdown occurs. Field plate does not change the critical electric field of silicon but reduces the peak value of electric field at a certain bias of drain and thus improves the device breakdown voltage. In an ideal case, when the device breaks down at off-state, the surface electric field is

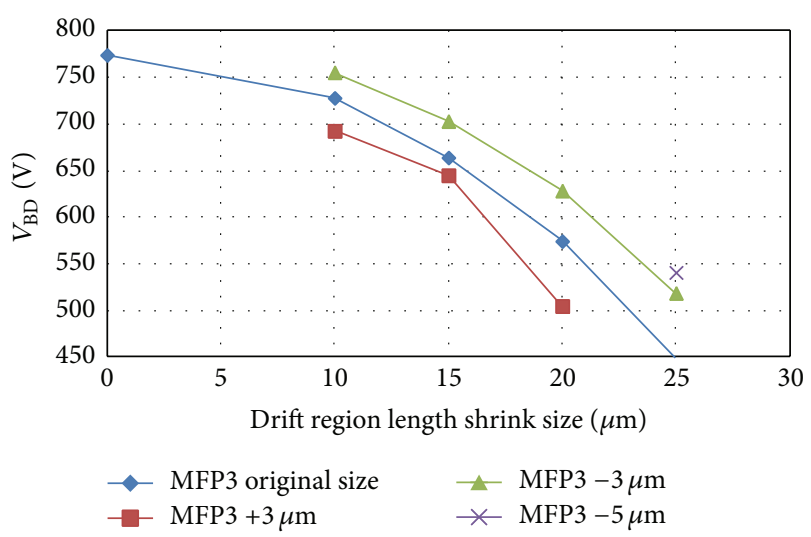

Figure 2: Breakdown voltage related to different drift length.

lower than $E_{c}$, which means the breakdown happens in the internal region of drift instead of on the surface of silicon. The breakdown of NLDMOS with field plate may not really occur in the internal region of drift, but the field plate can help to move the breakdown point away from the weak gate oxide region to field plate edge.

With the aid of process and device TCAD software, the different MFP and PFP designs and their effects on the breakdown voltage of $500 \mathrm{~V}$ NLDMOS have been simulated. The effect of different drift lengths also has been studied. In order to get a $500 \mathrm{~V}$ NLDMOS with shortest drift length and without scarifying breakdown voltage, the breakdown voltage drop caused by drift length shortening needs to be compensated by a dedicated field plate design.

Finally, a $500 \mathrm{~V}$ NLDMOS with small size and high breakdown voltage is obtained. The experiment result got from silicon matches the simulation data well and proves the correctness of study in this paper. This demonstrated $500 \mathrm{~V}$ high voltage NLDMOS meets the application requirement (higher than the $550 \mathrm{~V}$, as least $10 \%$ tolerance) and shows excellent on-resistance performance.

\section{The Impact of Metal Field Plate on Breakdown Voltage of NLDMOS}

4.1. Effect of Metal Field Plate (Drain Side, MFP3) on $V_{B D}$. Figure 2 shows how the breakdown voltage changes NLDMOS as drift length shrinks at different MFP3 sizes. In this figure, the drift length shrink means shorter drift length. The reduction of MFP3 size means the increase of space S2 between MFP2 and MFP3. With the same MFP3, the breakdown voltage drops as drift region becomes shorter. When drift length shrinks $10 \mu \mathrm{m}$, the breakdown voltage drops from $774 \mathrm{~V}$ to $728 \mathrm{~V}$ and decreases by $46 \mathrm{~V}$. If the drift length is determined, the breakdown voltage increases with smaller MFP3 size. When MFP3 is shortened by $3 \mu \mathrm{m}$, the breakdown voltage has an increase of $39 \mathrm{~V}$ and $51 \mathrm{~V}$, respectively, for drift length reduction of $15 \mu \mathrm{m}$ and $20 \mu \mathrm{m}$. It reveals that the breakdown voltage can be improved more effectively by MFP3 with shorter drift length. 

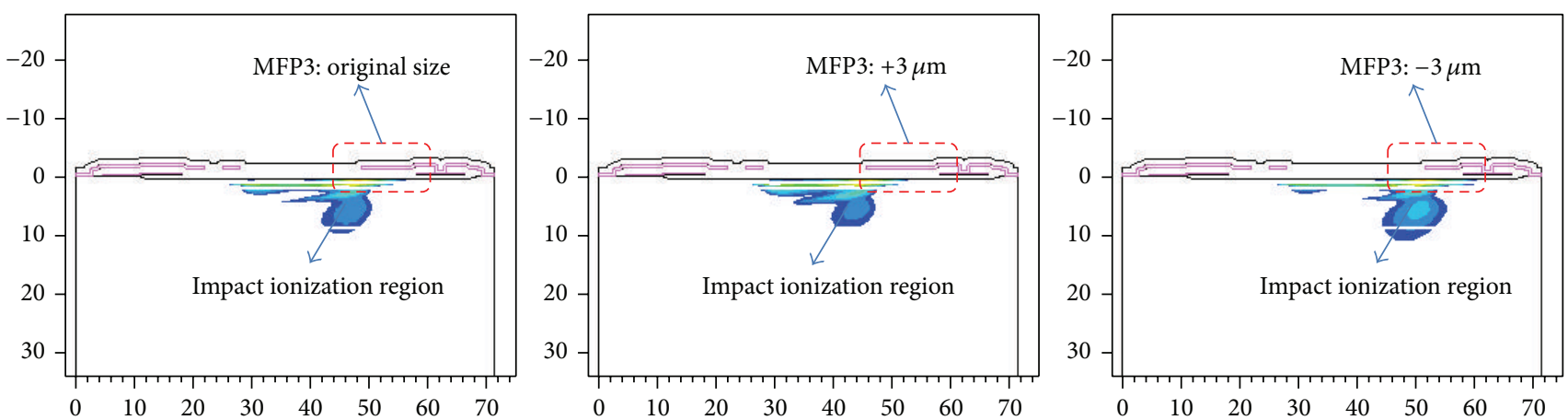

(a)

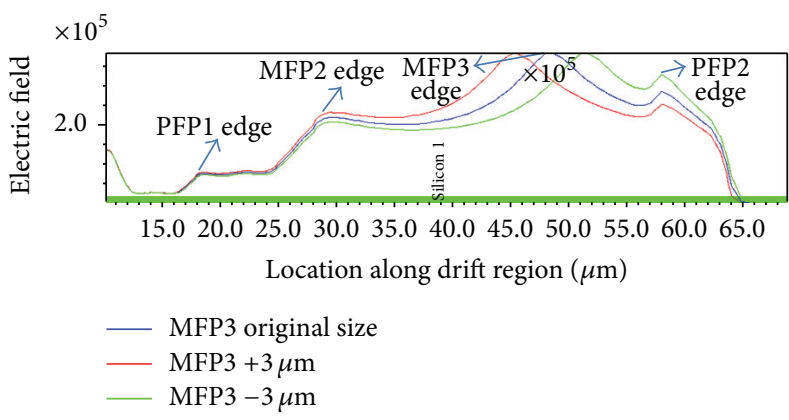

(b)

FIGURE 3: (a) Simulated impact ionization at breakdown voltage; (b) lateral electric field distribution of drift region from source to drain.

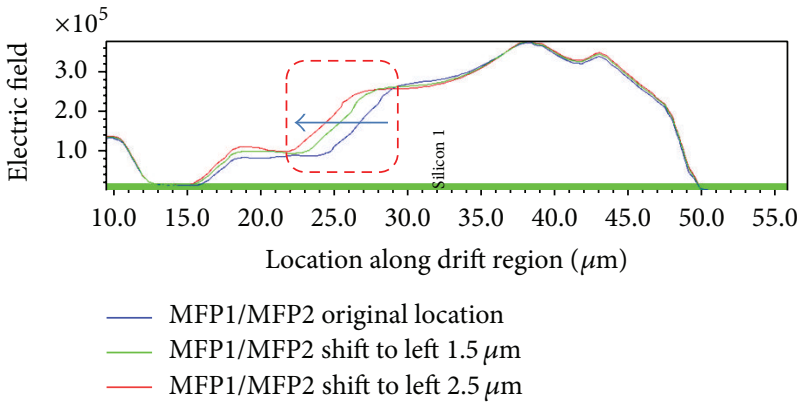

Figure 4: Lateral electric field distribution of different MFP2 location.

Figure 3(a) gives the impact ionization intensity pictures of 3 different MFP3 conditions: the length is changed $0 \mu \mathrm{m}$, $+3 \mu \mathrm{m}$, and $-3 \mu \mathrm{m}$. Based on the location of impact ionization, breakdown occurs at surface of drift region close to the left edge of MFP3. Figure 3(b) presents the lateral electric field distribution in the drift region from source to drain. It shows the electric field peaks locate at the right side edge of MFP2, the left side edges of MFP3 and PFP2. The highest one is peak at MFP3 edge and the breakdown also happens in this location. The electric field peak shifts to the drain side and breakdown voltage becomes higher when MFP3 size is reduced.

4.2. Effect of Metal Field Plate Location (Source Side) on $V_{B D}$. Figure 4 shows the simulation result of lateral electric
TABLE 2: $V_{\mathrm{BD}}$ of different PFP1 experiment.

\begin{tabular}{lc}
\hline PFP size experiment & $V_{\mathrm{BD}}$ \\
\hline 0 & 728 \\
PFP1 $-2 \mu \mathrm{m}$ & 728.1 \\
PFP1 $+2 \mu \mathrm{m}$ & 727.1 \\
\hline
\end{tabular}

field distribution with different MFP2 and MFP1 locations while keeping MFP3 size and space of MFP1 and MFP2 (S1) unchanged. According to the lateral electric field distribution shown in Figure 4, the electric field peak close to MFP2 right edge shifts to the left side as MFP1 and MFP2 shift to the left. Breakdown voltage increases by $44 \mathrm{~V}$ when the location changes by $2.5 \mu \mathrm{m}$. This reveals that the MFP2 location has effective impact on NLDMOS breakdown voltage. MFP2 moving to the left side helps to raise the breakdown voltage of the device.

\section{The Impact of Polyfield Plate on the Breakdown Voltage of NLDMOS}

Table 2 gives the simulation results of breakdown voltage for device with different PFP1 sizes. It shows that different PFP1 sizes have no obvious effect on breakdown voltage. The change of $V_{\mathrm{BD}}$ is less than $1 \mathrm{~V}$ when PFP1 increases or decreases by $2 \mu \mathrm{m}$.

Figure 5 is the lateral electric field distribution of PFP1 experiment. It shows the location of related electric field peak 


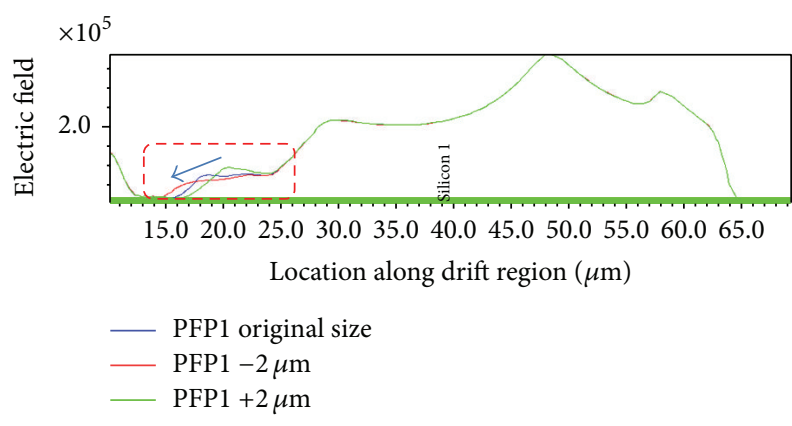

FIgURE 5: Lateral electric field distribution of different PFP1 size.

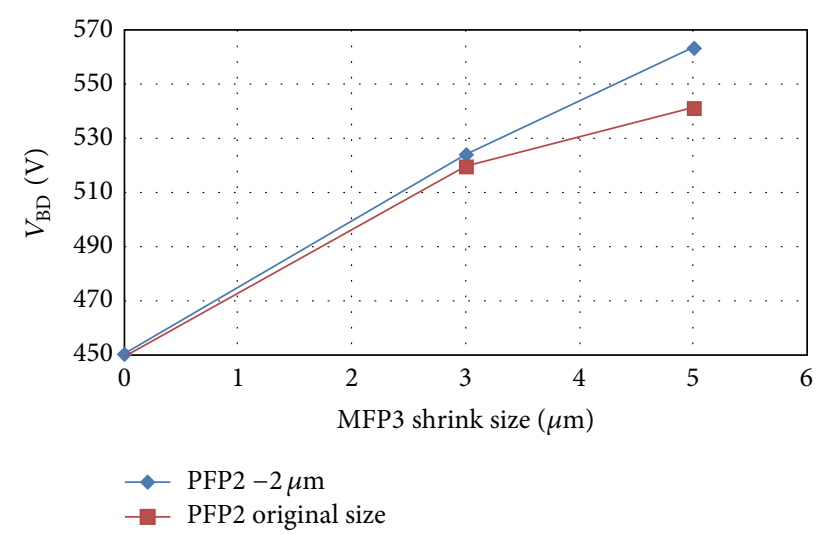

FIGURE 6: NLDMOS breakdown voltage related to MFP3 reducing sizes for different PFP2 length.

will shift as PFP1 edge location changes. The peak value in the left side is smaller than the right side.

\section{Coeffect of Metal Field Gate (MFP3) and Polyfield Gate (PFP2) on the Breakdown Voltage of NLDMOS}

From the above analysis, device with shorter MFP length shows higher breakdown voltage. Figure 6 tells that, at different PFP2 sizes, the improved level of breakdown voltage with the same MFP3 shrink is different. When MFP3 is reduced $3 \mu \mathrm{m}$, breakdown voltage is increased $70 \mathrm{~V}$ and $74 \mathrm{~V}$, respectively, for PFP2 without change and with $2 \mu \mathrm{m}$ reduction. The difference is $4 \mathrm{~V}$ and shorter PFP2 has higher breakdown voltage. When MFP3 continuously reduces by $5 \mu \mathrm{m}$, breakdown voltage increases by $92 \mathrm{~V}$ and $113 \mathrm{~V}$. Their difference is enlarged to $21 \mathrm{~V}$ and the shorter PFP2 still has higher $V_{\mathrm{BD}}$. The reason is that the highest electric field peak is changed from MFP3 left edge to PFP2 left edge as illustrated by Figure 7 .

In further analysis of the NLDMOS breakdown voltage considering more MFP3 and PFP2 splits as shown in Figure 8, every PFP2 size has an optimized value of the MFP3 extending over PFP2 (E1). NLDMOS with this optimized $E 1$ value has highest breakdown voltage. For different PFP2 size, the suitable $E 1$ is between $2 \mu \mathrm{m}$ and $5 \mu \mathrm{m}$. In the case of PFP2 original size, device with $E 1=4 \mu \mathrm{m}$ shows highest breakdown

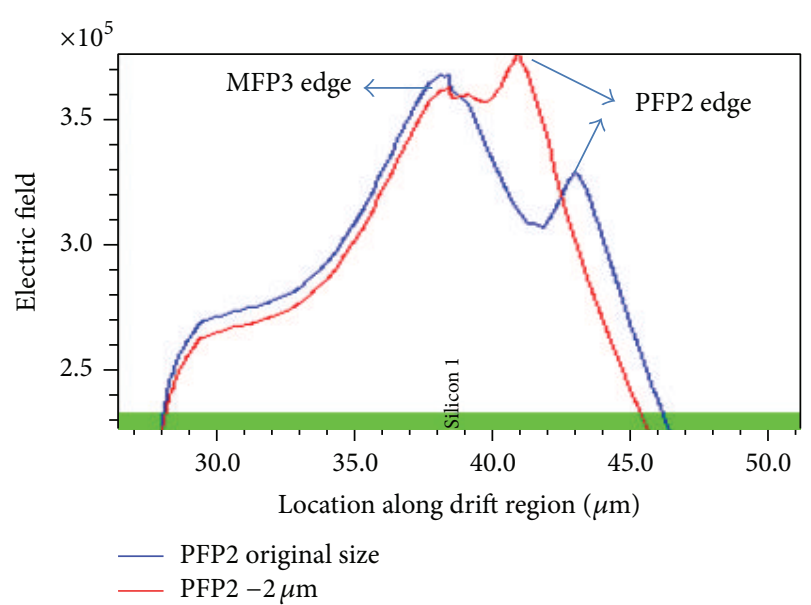

FIGURE 7: Lateral electric field distribution of MFP shrunk $5 \mu \mathrm{m}$ for PFP2 no change and with $2 \mu \mathrm{m}$ shrink.

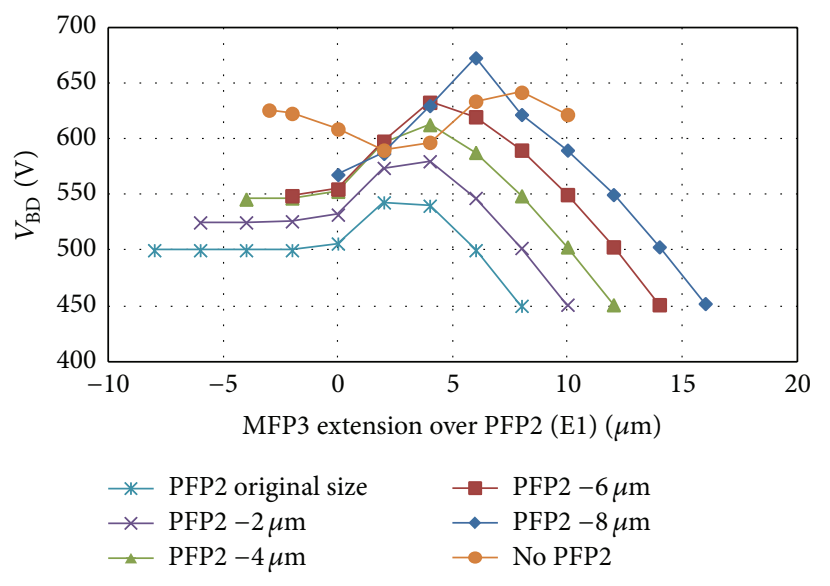

FIGURE 8: Breakdown voltage related to MFP3 extension over PFP2 (E1) for different PFP2 sizes.

voltage and $V_{\mathrm{BD}}$ starts to drop if $E 1$ becomes smaller than this value. When MFP3 is shrunk $5 \mu \mathrm{m}$, the $E 1$ is changed from $8 \mu \mathrm{m}$ to $3 \mu \mathrm{m}$ and the increase of breakdown voltage becomes less as Figure 6 shows.

\section{Experiment Results}

Based on the above study, a $500 \mathrm{~V}$ NLDMOS is designed with $30 \mu \mathrm{m}$ drift length shrunk as well as metal and polysilicon field plate optimized. The breakdown voltage of simulated result and measurement data are $594 \mathrm{~V}$ and $590 \mathrm{~V}$, respectively, as Figure 9 shows, and both results match well. The breakdown voltage meets the requirement of $500 \mathrm{~V}$ high voltage device.

Idvg characteristics curve of this device measured on silicon is in Figure 10. The $R_{\mathrm{sp}}$ calculated based on measured linear current of drain in Figure 10 is $7.88 \mathrm{ohm} * \mathrm{~mm}^{2}$ and is about $25 \%$ less than the released data from another commercial company. 
TABLE 3: Comparison of reference NLDMOS and this work.

\begin{tabular}{lccc}
\hline Item & Reference & This work & Difference \\
\hline $\begin{array}{l}\text { Length of drift } \\
\text { region }(\mu \mathrm{m})\end{array}$ & 67 & 37 & $45 \%$ \\
$V_{\mathrm{BD}}(\mathrm{V})$ & 772 & 590 & $24 \%$ \\
\hline
\end{tabular}

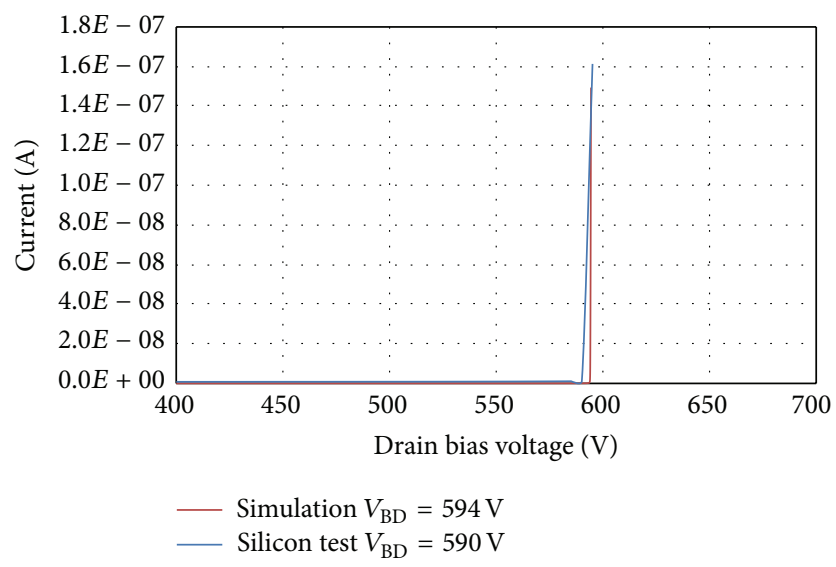

FIGURE 9: Breakdown voltage comparison of simulation and silicon data.

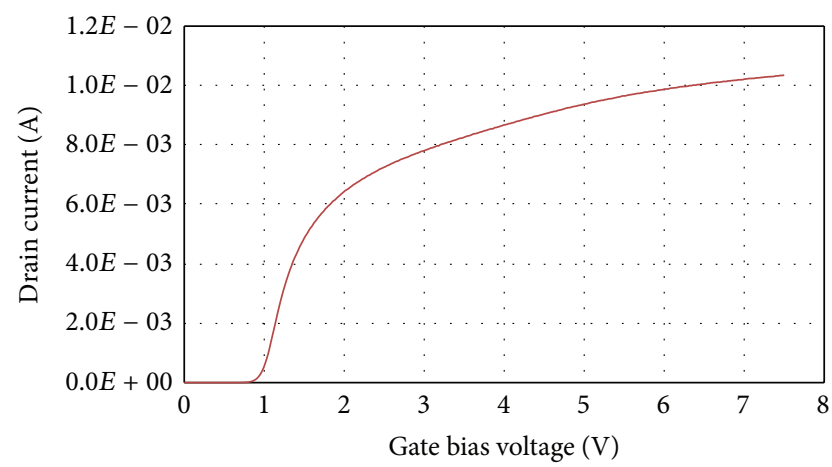

FIGURE 10: Idvg curve of this $500 \mathrm{~V}$ NLDMOS with area $=0.816 \mathrm{~mm}^{2}$ at $V_{\mathrm{dd}}=0.1 \mathrm{~V}$. The $R_{\mathrm{sp}}$ is $7.88 \mathrm{ohm} * \mathrm{~mm}^{2}$.

Compared with the referenced NLDMOS with $67 \mu \mathrm{m}$ drift region length, the drift region of new device is shrunk by $47 \%$. However, the $V_{\mathrm{BD}}$ of optimized $500 \mathrm{~V}$ NLDMOS is $590 \mathrm{~V}$ and only decreases by $24 \%$ compared to the $V_{\mathrm{BD}}$ of the reference one. It means that the breakdown voltage of the $500 \mathrm{~V}$ NLDMOS is improved a lot by this MFP and PFP design discussed in this paper. The result is summarized in Table 3.

\section{Conclusion}

Study of a $500 \mathrm{~V}$ high voltage NLDMOS and related field plate designs have been presented in this paper. The effect of metal and polysilicon field plate on the breakdown voltage has been investigated and the coeffect between MFP3 and PFP2 has also been studied. With the aid of research result, a demonstrated $500 \mathrm{~V}$ NLDMOS with $37 \mu \mathrm{m}$ drift length and optimized field plate design achieves breakdown voltage of $590 \mathrm{~V}$ and $R_{\mathrm{sp}}$ of $7.88 \mathrm{ohm} * \mathrm{~mm}^{2}$. This excellent onresistance performance is about $25 \%$ less than the released data from another commercial company. The simulation and silicon data match well. The breakdown voltage has been greatly improved by proper field plate design. So the research result of MFP and PFP in this paper can be selected as a good reference for other high voltage designs. But the study on field plate presented in this paper does not consider the doping RESURF of drift region. It will be a direction in the further research of $500 \mathrm{~V}$ high voltage NLDMOS.

\section{Conflict of Interests}

The authors declare that there is no conflict of interests regarding the publication of this paper.

\section{References}

[1] J. A. Appels and H. M. J. Vaes, "High voltage thin layer devices (RESURF devices)," in Proceedings of the IEEE International Electron Devices Meeting (IEDM '79), vol. 25, pp. 238-241, 1979.

[2] A. W. Ludikhuize, "A review of RESURF technology," in Proceedings of the IEEE 12th International Symposium on Power Semiconductor Devices and ICs (ISPSD '00), pp. 11-18, 2000.

[3] D. R. Disney, A. K. Paul, M. Darwish, R. Basecki, and V. Rumennik, "A new 800 V lateral MOSFET with dual conduction paths," in Proceedings of the 13th International Symposium on Power Semiconductor Devices and ICs (ISPSD '01), pp. 399-402, Osaka, Japan, June 2001.

[4] M. Qiao, Y. F. Li, X. Zhou, Z. J. Li, and B. Zhang, "A 700$\mathrm{V}$ junction-isolated triple RESURF LDMOS with N-type top layer," IEEE Electron Device Letters, vol. 35, no. 7, pp. 774-776, 2014.

[5] S. Banerjee, V. Parthasarathy, and M. Manley, "Design of stable $700 \mathrm{~V}$ lateral MOSFET for new generation, low-cost off-line SMPS," in Proceedings of the 22nd International Symposium on Power Semiconductor Devices and IC's (ISPSD '10), pp. 269-272, IEEE, June 2010.

[6] M. Venturato, G. Cantone, F. Ronchi, and F. Toia, "A novel $0.35 \mu \mathrm{m} 800 \mathrm{~V}$ BCD technology platform for offline applications," in Proceedings of the 24th International Symposium on Power Semiconductor Devices and ICs (ISPSD '12), pp. 397-400, June 2012.

[7] A. Wood, C. Dragon, and W. Burger, "High performance silicon LDMOS technology for $2 \mathrm{GHz}$ RF power amplifier applications," in Proceedings of the IEEE International Electron Devices Meeting, pp. 87-90, December 1996.

[8] D. C. Burdeaux and W. R. Burger, "Intrinsic reliability of RF power LDMOS FETs," in Proceedings of the IEEE International Reliability Physics Symposium (IRPS '11), pp. 435-443, April 2011.

[9] T. Miyoshi, T. Tominari, Y. Hayashi et al., "Reliability improvement in field-MOS FETs with thick gate oxide for 300-V applications," in Proceedings of the 25th IEEE International Symposium on Power Semiconductor Devices and ICs (ISPSD '13), pp. 393-396, 2013.

[10] K. Mao, M. Qiao, L. Jiang et al., "A $0.35 \mu \mathrm{m} 700 \mathrm{v}$ BCD technology with self-isolated and non-isolated ultra-low specific on-resistance DB-nLDMOS," in Proceedings of the 25th International Symposium on Power Semiconductor Devices and IC's (ISPSD '13), pp. 397-400, Kanazawa, Japan, May 2013. 
[11] Z. Hossain, "Determination of manufacturing RESURF process window for a robust $700 \mathrm{~V}$ double RESURF LDMOS transistor," in Proceedings of the 20th International Symposium on Power Semiconductor Devices and IC's (ISPSD '08), pp. 133-136, Orlando, Fla, USA, May 2008. 

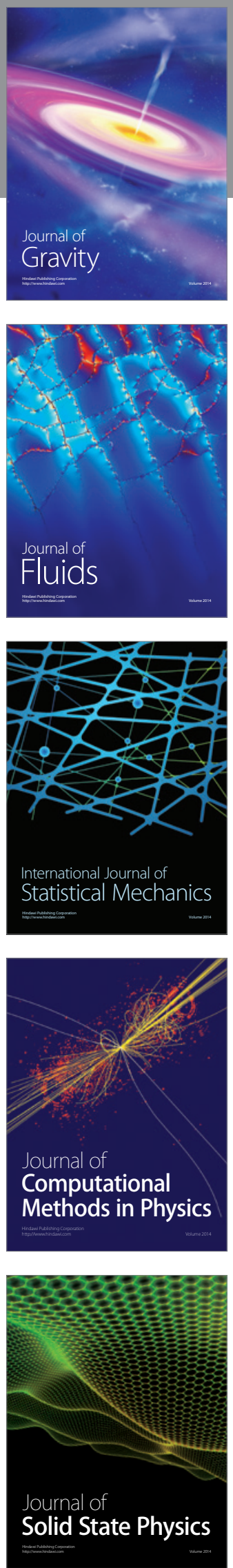

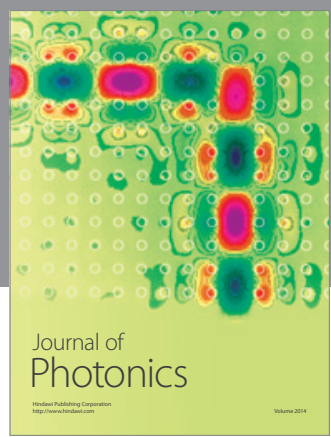

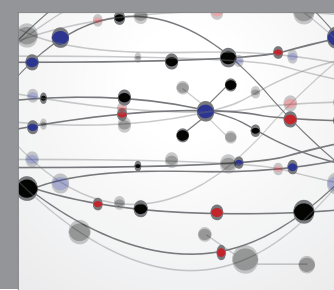

The Scientific World Journal

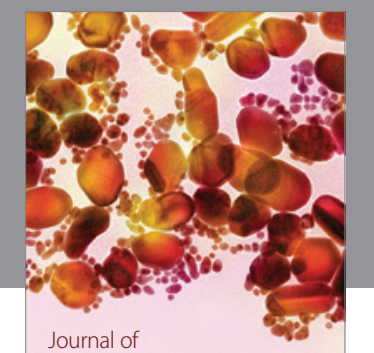

Soft Matter
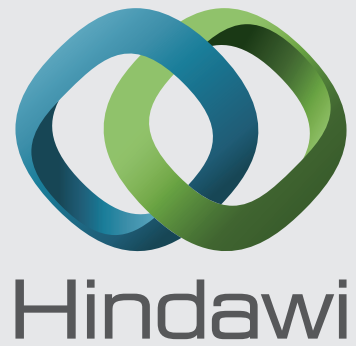

Submit your manuscripts at

http://www.hindawi.com
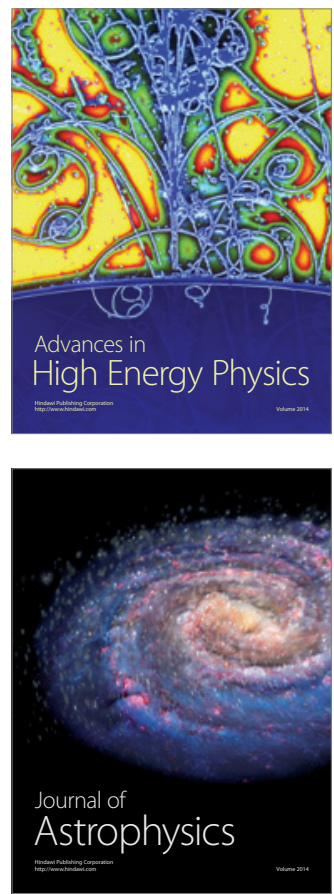
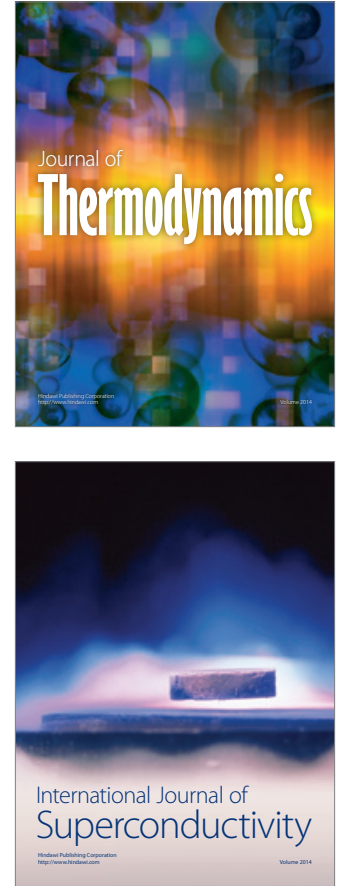
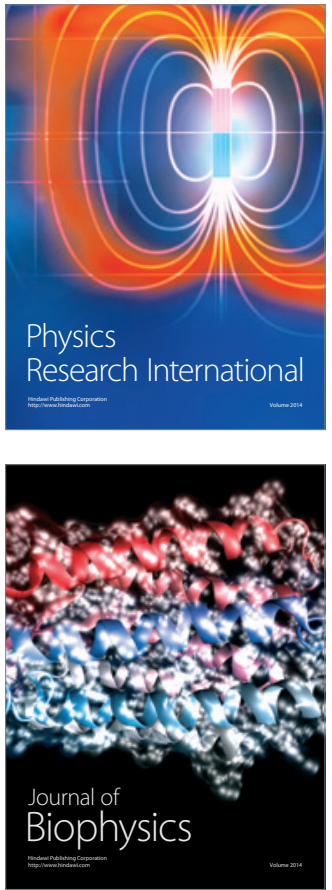
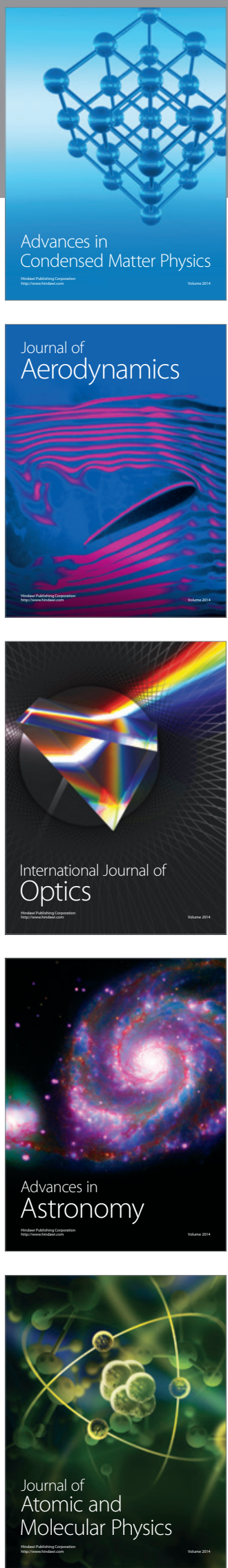